\title{
Pulsed-Wave Doppler Ultrasound Mode
}

National Cancer Institute

\section{Source}

National Cancer Institute. Pulsed-Wave Doppler Ultrasound Mode. NCI Thesaurus. Code C130064.

A method of ultrasound imaging that uses intermittent Doppler signals to measure both direction and velocity of blood flow. 